\title{
The development of a community-based public health response to an outbreak of post- streptococcal glomerulonephritis in a First Nations community
}

\author{
Jeffrey Jacob¹, Natalie Bocking ${ }^{1}$, Ruben Hummelen², Jenna Poirier², Len Kelly ${ }^{3 \star}$, Sharen Madden², \\ Yoko Schreiber $2,3,4$
}

\begin{abstract}
Background: Post-streptococcal glomerulonephritis (PSGN) is a rare immune-mediated condition that typically occurs in children as a result of group A streptococcus (GAS) infection. PSGN is not considered a disease of public health significance, or reportable, in Canada. Higher incidence of PSGN has been described among Indigenous people in Canada. No national or provincial guidance exists to define or manage PSGN outbreaks.
\end{abstract}

Objective: To describe an outbreak of seven paediatric cases of PSGN in a remote First Nations community in northwestern Ontario and the development of a community-wide public health response.

Methods: Following a literature review, an intervention was developed involving screening of all children in the community for facial or peripheral edema or skin sores, and treatment with antibiotics if noted. Case, contact and outbreak definitions were also developed. The purpose of the response was to break the chain of transmission of a possible nephritogenic strain of streptococcus circulating in the community. Relevant demographic, clinical and laboratory data were collected on all cases.

Outcome: Seven paediatric cases of PSGN presented to the community nursing station between September 25 and November 29, 2017. Community-wide screening for skin sores was completed for $95 \%$ of the community's children, including 17 household contacts, and as a result, the last of the cases was identified. Nineteen adult household contacts were also screened. Ten paediatric contacts and two adult contacts with skin sores were treated with one dose of intramuscular penicillin, and six paediatric contacts received oral cephalexin. No further cases were identified following the screening.

Conclusion: PSGN continues to occur in Indigenous populations worldwide at rates higher than in the overall population. In the absence of mandatory reporting in Canada, the burden of PSGN remains underappreciated and could undermine upstream and downstream public health interventions. Evidence-based public health guidance is required to manage outbreaks in the Canadian context. The community-based response protocol developed to contain the PSGN outbreak in this First Nations community can serve as a model for the management of future PSGN outbreaks.
This work is licensed under a Creative Commons Attribution 4.0 International License.

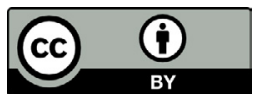

Affiliations

1 Sioux Lookout First Nations Health Authority, Sioux Lookout, $\mathrm{ON}$

${ }^{2}$ Northern Ontario School of Medicine, Sioux Lookout, ON

${ }^{3}$ Sioux Lookout Meno Ya Win Health Centre, Sioux Lookout, ON

${ }^{4}$ Max Rady College of Medicine, University of Manitoba, Winnipeg, $\mathrm{MB}$

*Correspondence:

Ikelly@mcmaster.ca

Suggested citation: Jacob J, Bocking N, Hummelen R, Poirier J, Kelly L, Madden S, Schreiber S.

The development of a community-based public health response to an outbreak of post-streptococcal glomerulonephritis in a First Nations community. Can Commun Dis Rep 2021;47(7/8):339-46.

https://doi.org/10.14745/ccdr.v47i78a07

Keywords: post-streptococcal glomerulonephritis, outbreak, First Nations, community-based intervention 


\section{Background}

Post-streptococcal glomerulonephritis (PSGN) is considered a rare non-suppurative sequela of group $A$ streptococcus (GAS) infection, affecting children more commonly than adults. Symptoms of nephritis, which include edema, hypertension and hematuria, typically manifest 2 to 6 weeks after GAS skin infection or streptococcal pharyngotonsillitis (1-3). Short-term prognosis is generally favourable, although renal function can be affected in later years (4).

Under current public health legislation, PSGN is not a reportable disease in Ontario or any other Canadian province, and as a result, provincial and national level incidence rates are unknown (5). Globally, PSGN remains a disease of social inequity, affecting children in low-income settings; young Indigenous people carry a higher burden in high-income countries such as Australia (4).

A case series has documented similarly high disease burden among First Nations communities in northwestern Ontario (6). Canadian efforts against GAS disease are targeted mainly towards invasive GAS (iGAS), such as toxic-shock syndrome and soft-tissue necrosis (7). No Canadian guidance for the public health management of PSGN is available.

\section{Setting}

An outbreak of PSGN occurred in a remote, fly-in First Nations community in northwestern Ontario with a population of approximately 900 people. Federal nurses provide primary care and public health services at the community nursing station. Physicians visit for a week each month and also provide 24/7 telephone support.

This outbreak report was requested by the community leadership and approved by the Sioux Lookout Meno Ya Win Health Centre Research Review and Ethics Committee.

This article documents the outbreak of PSGN in the First Nations community and the development of a public health response intervention to prevent the spread of nephritogenic strains of GAS to other children.

\section{Presentation and response}

On October 26, 2017, a front-line nurse reported to her manager a cluster of children presenting with possible PSGN to the community nursing station. In total, six cases presented between September 25 and November 17, 2017. The concern was brought forward to the federal agency, First Nations and Inuit Health, Ontario Region, Indigenous Services Canada (ISC) and the local Indigenous health services organization, Sioux Lookout First Nations Health Authority (SLFNHA). Representatives from First Nations and Inuit Health, ISC and SLFNHA met with local clinicians to determine if the cases constituted an outbreak and to develop an evidence-based response. The ISC medical officer also met with the community leadership to request their support in raising awareness and to engage the community in a collaborative response. The nursing station personnel also played a key role in engaging the community. The purpose of the response was to break the chain of transmission of a possible nephritogenic strain of streptococcus circulating in the community. An outbreak was declared on November 21, 2017.

\section{Phase 1: Detection and declaration of outbreak}

\section{Case definition}

A chart review was conducted to collect demographic, clinical and laboratory information and to ensure patients met the case definition for PSGN (see Table 1). Clinical data were collected by community nurses and physicians retrospectively for cases identified before the declaration of the outbreak and prospectively during community screening and contact tracing.

\section{Table 1: Case definitions of PSGN developed for use in outbreak containment in a First Nations community in northwestern Ontario, 2017}

\begin{tabular}{|l|l|}
\hline Confirmed case & $\begin{array}{l}\text { Definitive evidence; or clinical and laboratory } \\
\text { evidence }\end{array}$ \\
\hline Probable case & Clinical evidence only \\
\hline Possible case & Laboratory evidence only or expert opinion \\
\hline Evidence description \\
\hline $\begin{array}{l}\text { Definitive } \\
\text { evidence }\end{array}$ & Renal biopsy suggestive of PSGN \\
\hline \multirow{2}{*}{$\begin{array}{l}\text { Clinical } \\
\text { evidence (at } \\
\text { least two of the } \\
\text { four required) }\end{array}$} & Facial edema \\
\cline { 2 - 2 } & Peripheral edema \\
\cline { 2 - 2 } & Hypertension \\
\hline \multirow{2}{*}{$\begin{array}{l}\text { Laboratory } \\
\text { evidence (all } \\
\text { three required) }\end{array}$} & $\begin{array}{l}\text { Evidence of recent streptococcal infection (throat or } \\
\text { skin culture or elevated ASOT) }\end{array}$ \\
\cline { 2 - 2 } & Reduced complement C3 level \\
\hline
\end{tabular}

Abbreviations: ASOT, antistreptolysin-O titre; PSGN, post-streptococcal glomerulonephritis Source: Department of Health and Families, 2010 (8)

Patients were clinically assessed for hypertension, facial and peripheral edema, skin sores and scabies, and hematuria on urinalysis. Skin and throat swabs for culture were obtained if indicated. Laboratory investigation included blood urea nitrogen (BUN), creatinine $(\mathrm{Cr})$, complete blood count (CBC), antistreptolysin-O titre (ASOT) and complement C3. Clinical management was provided by the community family physicians who consulted with a paediatrician.

\section{Outbreak definition}

We searched the literature for national and international evidence-based guidance on the definition and public health management of PSGN outbreaks, particularly in Indigenous communities. No Canadian resources were found, but grey 
literature from Australia provided guidelines that were largely based on expert opinion and local experience $(8,9)$. Based on their community screening criteria, an outbreak of PSGN was defined as:

- Two or more probable or confirmed cases in the same community with onset within one week of each other and with at least one case with a reduced complement $\mathrm{C} 3$

OR

- One confirmed case and two probable cases in the same community, with onset within one month of each other

The Australian guidelines included in their criteria that "the cases are not contacts of each other" $(8,9)$. We were unable to determine in a timely fashion whether the cases in the First Nations community were contacts of each other and removed this criterion from our definition of a PSGN outbreak.

An outbreak of PSGN was declared by the ISC medical officer on November 21, 2017. A multi-jurisdictional outbreak management team was formed. This team included ISC personnel, the public health physician from the SLFNHA, an infectious disease specialist from Sioux Lookout, the community family physicians and the nursing station manager. The community health director played a crucial role in the response.

An outbreak management protocol was developed based on approaches used in Western Australia and Northern Territory, Australia $(8,9)$. These are described in the following sections.

\section{Contact definition}

Close contacts were defined as individuals who had stayed overnight in the house of a confirmed case in the two weeks preceding the onset of their illness. Both adult and child contacts of confirmed cases were identified and assessed by community health nurses. Contacts were examined for the presence of skin sores, scabies, facial and peripheral edema, and hematuria; their blood pressure was measured and recorded.

\section{Phase 2: Immediate control measures}

Educational materials were developed according to community needs and distributed widely through a variety of communication channels.

The community health nurses received education in early case detection.

The cases, analyses and treatment are described in the section "Descriptive epidemiology."

\section{Phase 3: Community-wide screening}

Screening of the community took place from November 27 to December 3, 2017. All children and youth between 12 months and 17 years old were eligible for screening. The list of eligible children was developed from the community member evacuation list for regional forest fire management. Screening was implemented over a one-week period and took place first at the Band Office and then at the community nursing station to minimize disruption to regular primary care services. Screening was led by nurses who have an ongoing relationship with the community.

The children were screened for skin sores, scabies, and facial or peripheral edema (Table 2). Contact tracing and treatment occurred concurrently. Informed consent was obtained prior to assessment so that skin sores or scabies could be treated during the same visit.

\section{Table 2: Diagnostic criteria for confirmed or suspected PSGN cases in a First Nations community in northwestern Ontario, September 25 to December 10, 2017}

\begin{tabular}{|c|c|c|c|c|c|c|c|}
\hline $\begin{array}{c}\text { Diagnostic } \\
\text { criteria }\end{array}$ & $\begin{array}{c}\text { Case } \\
1\end{array}$ & $\begin{array}{c}\text { Case } \\
2\end{array}$ & $\begin{array}{c}\text { Case } \\
3\end{array}$ & $\begin{array}{c}\text { Case } \\
4\end{array}$ & $\begin{array}{c}\text { Case } \\
5\end{array}$ & $\begin{array}{c}\text { Case } \\
6\end{array}$ & $\begin{array}{c}\text { Case } \\
7\end{array}$ \\
\hline \multicolumn{8}{|c|}{ Definite evidence } \\
\hline Renal biopsy & $\begin{array}{l}\text { No } \\
\text { biopsy }\end{array}$ & $\begin{array}{l}\text { No } \\
\text { biopsy }\end{array}$ & $\begin{array}{l}\text { No } \\
\text { biopsy }\end{array}$ & $\begin{array}{l}\text { No } \\
\text { biopsy }\end{array}$ & + & $\begin{array}{l}\text { No } \\
\text { biopsy }\end{array}$ & $\begin{array}{l}\text { No } \\
\text { biopsy }\end{array}$ \\
\hline \multicolumn{8}{|c|}{ Clinical evidence (2 of 4 required) } \\
\hline Facial edema & + & + & + & + & + & + & - \\
\hline $\begin{array}{l}\text { Peripheral } \\
\text { edema }\end{array}$ & - & - & - & - & - & - & - \\
\hline $\begin{array}{l}\text { Moderate } \\
\text { hematuria on } \\
\text { dipstick }\end{array}$ & + & + & + & + & + & + & + \\
\hline Hypertension & + & $+^{a}$ & + & + & + & + & $+^{a}$ \\
\hline \multicolumn{8}{|c|}{ Laboratory evidence ( 3 of 3 required) } \\
\hline $\begin{array}{l}\text { Hematuria on } \\
\text { microscopy }\end{array}$ & + & + & + & + & + & + & - \\
\hline $\begin{array}{l}\text { Evidence } \\
\text { of recent } \\
\text { streptococcal } \\
\text { infection } \\
\text { (throat or } \\
\text { skin culture } \\
\text { or elevated } \\
\text { ASOT) }\end{array}$ & + & + & + & + & + & + & + \\
\hline $\begin{array}{l}\text { Reduced } \\
\text { complement } \\
\text { C3 level }\end{array}$ & + & + & + & + & + & + & + \\
\hline
\end{tabular}




\section{Contact tracing, community screening and management}

A total of 36 household contacts were identified, with 17 contacts between 1 and 17 years old and 19 contacts over 17 years old. Of the contacts, all the adults and all but one child were screened (see Table 3). In our protocol, paediatric contacts received one dose of intramuscular benzathine penicillin or an alternative, whether skin sores were present or not; 10 of the 17 paediatric contacts were treated with intramuscular penicillin and seven with oral cephalexin. Of the 19 adult contacts, two had skin sores and were treated with intramuscular penicillin; only the adult contacts who had skin sores were treated.

Table 3: Community screening for PSGN cases in a First Nations community in northwestern Ontario, November 27 to December 3, 2017

\begin{tabular}{|l|r|r|r|r|r|}
\hline \multirow{2}{*}{ Characteristics } & \multicolumn{4}{|c|}{ Screened population } & \multirow{2}{*}{ Children } \\
\cline { 2 - 5 } & \multicolumn{3}{|c|}{ Total } \\
\cline { 2 - 6 } & $\begin{array}{c}\text { Total of } \\
\text { participants }\end{array}$ & Contacts & Non-contacts & Contacts & \\
\hline $\begin{array}{l}\text { Eligible for } \\
\text { screening }\end{array}$ & 224 & 17 & 207 & 19 & 243 \\
\hline Screened & 212 & 16 & 196 & 19 & 231 \\
\hline Refused screening & 12 & 1 & 11 & 0 & 12 \\
\hline New cases & 1 & 1 & 0 & 0 & 0 \\
\hline Treated & 20 & $16^{\mathrm{a}}$ & $4^{\mathrm{b}}$ & $2^{\mathrm{b}}$ & 22 \\
\hline Penicillin G & 11 & 10 & 1 & 2 & 13 \\
\hline Cephalexin & 10 & 7 & 3 & 0 & 10 \\
\hline
\end{tabular}

Abbreviation: PSGN, post-streptococcal glomerulonephritis

Three with skin sores

b With skin sore

No cases of scabies were identified.

As shown in Table 3, 95\% (212/224) of eligible children/youth, including the contacts noted above, were screened. Prevalence of skin sores was low (2.0\%). Community screening identified the seventh case of PSGN.

\section{Descriptive epidemiology}

Five cases presented to the community nursing station between September 25 and October 28, 2017. A sixth case presented on November 17, 2017, when concerns about a possible outbreak were being raised. A seventh possible case was identified during contact tracing/community screening on November 29 and confirmed on December 10, 2017.

The epidemiologic curve for the outbreak is shown in Figure 1. No additional cases were identified in the three years following the outbreak.
Figure 1: Epidemiologic curve of cases of suspected or confirmed ${ }^{\text {PSGN }}$ in a First Nations community in northwestern Ontario, September 25 to December 10, 2017

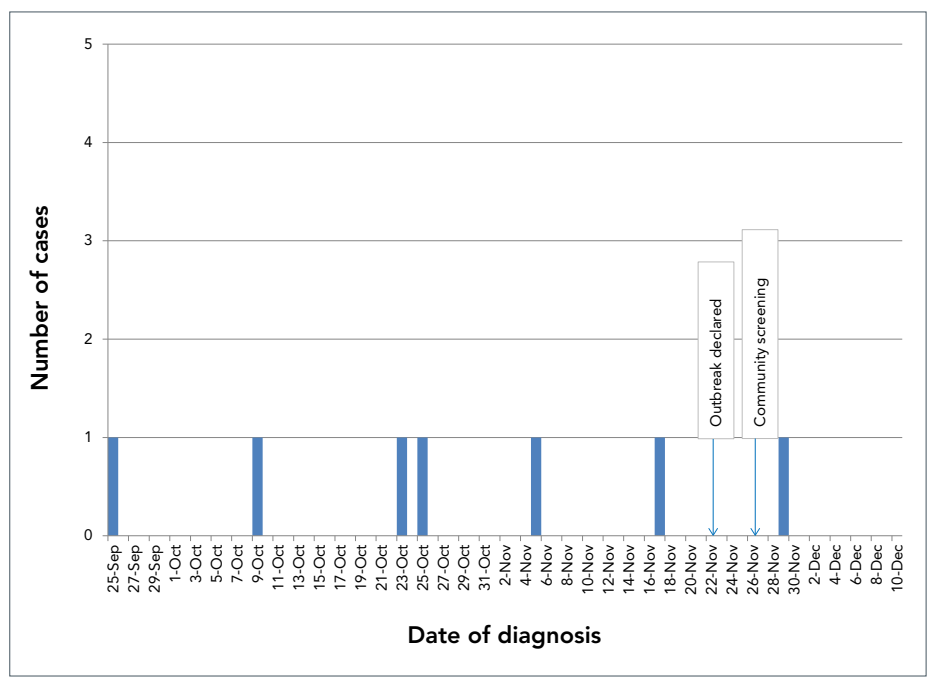

Abbreviation: PSGN, post-streptococcal glomerulonephritis

a Case \#7 presented in November 29, but was confirmed on December 10; the presentation was ill-defined. In this case, the confirmatory date is used in the epidemiologic curve

The seven patients were between 3 and 13 years old; five were male. Clinical and laboratory information for case confirmation is shown in Table 3 and Table 4. Almost all the patients presented with facial edema (6/7) and hypertension was common (5/7). Six of the seven children had concurrent or antecedent skin infection, four of which were GAS positive, and three children had throat swabs confirming GAS. One case with a negative throat swab and no skin findings was found to have a high ASOT

Of the seven PSGN cases, six patients required antihypertensive therapy and five required diuretics; all seven patients-the six confirmed and one initially probable case-were prescribed antibiotics. Six were hospitalized (Table 4); five were transferred to tertiary care paediatric hospitals for up to 16 days, including one who was admitted to the intensive care unit. Recovery was complete in four children; three had ongoing hematuria at their two-year follow-up. 
Table 4: Clinical presentation and laboratory evidence, treatment and outcomes for PSGN cases in a First Nations community in northwestern Ontario, 2017

\begin{tabular}{|c|c|c|c|c|c|c|c|}
\hline Clinical data & Case 1 & Case 2 & Case 3 & Case 4 & Case 5 & Case 6 & Case 7 \\
\hline Age range, years & $3-6$ & $10-13$ & $3-6$ & $3-6$ & $3-6$ & $10-13$ & $3-6$ \\
\hline Sex & M & $M$ & M & $\mathrm{F}$ & $\mathrm{F}$ & M & M \\
\hline $\begin{array}{l}\text { Day of presentation of confirmed or } \\
\text { suspected PSGN }\end{array}$ & 0 & 14 & 28 & 30 & 41 & 64 & 76 \\
\hline \multicolumn{8}{|l|}{ Clinical presentation } \\
\hline Initial blood pressure & $170 / 115$ & $128 / 77$ & $168 / 123$ & $147 / 117$ & $150 / 112$ & $150 / 88$ & $112 / 64$ \\
\hline Edema & $\begin{array}{r}\text { Facial, } \\
\text { pedal }\end{array}$ & Facial & Facial & Facial & Facial & Facial & - \\
\hline Pharyngitis & - & - & - & - & - & - & - \\
\hline Skin sores & + & + & + & + & + & - & + \\
\hline \multicolumn{8}{|l|}{ Proteinuriab } \\
\hline Macroscopic hematuria & + & - & + & + & + & + & - \\
\hline Decreased urine output & - & - & + & - & + & - & - \\
\hline Lethargy, anorexia & + & + & + & + & + & + & - \\
\hline \multicolumn{8}{|l|}{ Laboratory assessments $^{c}$} \\
\hline Hemoglobin (105-140 g/L) & 102 & 67 & 102 & 117 & 102 & 117 & 98 \\
\hline BUN (2.5-6.1 mmol/L) & 4.8 & 16.1 & 6.6 & 9.4 & 15.1 & 6.2 & 4.5 \\
\hline Creatinine $(46-92 \mu \mathrm{mol} / \mathrm{L})$ & 79.4 & 173 & 47.5 & 43.5 & 195 & 60 & 38 \\
\hline Complement C3 (0.88-1.65 g/L) & $<0.4$ & $<0.4$ & $<0.4$ & $<0.4$ & $<0.4$ & $<0.4$ & $<0.4$ \\
\hline ASOT (<200 IU/mL) & N/A & N/A & $>1,600$ & $800-1,600$ & 1,600 & 397 & $\mathrm{~N} / \mathrm{A}$ \\
\hline Microscopic hematuria ( $\leq 3 / \mathrm{HPF})$ & $\begin{array}{r}30 \text { and } \\
\text { more }\end{array}$ & $20-51$ & $\begin{array}{r}30 \text { and } \\
\text { more }\end{array}$ & $\begin{array}{r}30 \text { and } \\
\text { more }\end{array}$ & $\begin{array}{l}100 \text { and } \\
\text { more }\end{array}$ & $20-51$ & $\leq 3$ \\
\hline Throat culture & +GAS & $-G A S$ & + GAS & - GAS & $-\mathrm{GAS}$ & $+\mathrm{GAS}$ & N/A \\
\hline Skin lesion culture & Not done ${ }^{d}$ & $+\mathrm{GAS}$ & + GAS & Not done ${ }^{d}$ & $+\mathrm{GAS}$ & Not done ${ }^{d}$ & + GAS \\
\hline \multicolumn{8}{|l|}{ Treatment } \\
\hline \multicolumn{8}{|l|}{ Antihypertensive } \\
\hline Beta blocker & N/A & N/A & $\mathrm{N} / \mathrm{A}$ & + & N/A & $\mathrm{N} / \mathrm{A}$ & N/A \\
\hline $\mathrm{Ca}^{++}$channel blocker & + & N/A & + & + & N/A & + & N/A \\
\hline ACE inhibitor & N/A & + & N/A & N/A & N/A & N/A & N/A \\
\hline Vasodilator/alpha-agonist & N/A & N/A & + & + & + & + & $\mathrm{N} / \mathrm{A}$ \\
\hline Diuretic - furosemide & + & N/A & + & + & + & + & $\mathrm{N} / \mathrm{A}$ \\
\hline \multicolumn{8}{|l|}{ Antibiotic } \\
\hline Penicillin & N/A & N/A & $\mathrm{N} / \mathrm{A}$ & N/A & N/A & + & + \\
\hline Amoxicillin & + & N/A & + & N/A & N/A & $\mathrm{N} / \mathrm{A}$ & N/A \\
\hline Ceftriaxone & N/A & N/A & + & + & N/A & N/A & N/A \\
\hline Cephalexin & N/A & + & $\mathrm{N} / \mathrm{A}$ & N/A & + & N/A & N/A \\
\hline Azithromycin & N/A & N/A & $\mathrm{N} / \mathrm{A}$ & + & N/A & $\mathrm{N} / \mathrm{A}$ & N/A \\
\hline Fluid restriction & + & - & - & + & + & - & - \\
\hline Disposition & N/A & N/A & N/A & N/A & N/A & $\mathrm{N} / \mathrm{A}$ & N/A \\
\hline Length of hospital stay, days & 5 & 7 & 9 & 1 & 16 & 12 & 0 \\
\hline Outcome & Ongoing & Resolved & Ongoing & Resolved & Ongoing & Resolved & Resolved \\
\hline
\end{tabular}

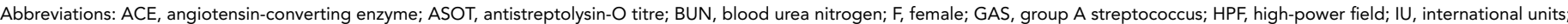

M, male; N/A, not available; PSGN, post-streptococcal glomerulonephritis; -, absent; +, present

Counted from date of first case

Although proteinuria is determined via a laboratory test, it is listed as a clinical presentation because it was measured at the community nursing station

c Values in parentheses are the normal ranges

The swab was not performed 


\section{Discussion}

PSGN outbreaks have been reported in several Indigenous communities in Australia, but this is the first outbreak reported in Canada (4,10-12). A 2016 six-year review of sporadic PSGN cases in northwest Ontario documented 10 paediatric and five adult cases, an incidence triple that of developed countries, but the review found no clustering of cases in any one community (6). This identification of an outbreak of PSGN in a remote First Nations community adds to the growing body of evidence of the disparate burden of post-streptococcal sequelae carried by Indigenous peoples in Canada and worldwide.

Because there is no national or provincial public health guidance to define or manage outbreaks of PSGN in Canada, we developed a community-based response protocol modelled on interventions used in Indigenous communities in Australia. The protocol and process can serve as a model for the management of future PSGN outbreaks.

Other GAS-related disease is also prevalent regionally: iGAS infections and an acute rheumatic fever, another immune-mediated GAS complication, occur at rates 10 and 75 times higher, respectively, than overall provincial rates (13-15). A spike in invasive GAS cases was observed in the two health units spanning northwestern Ontario in 2017, with emm74 and emm81 being the most prevalent strains circulating that year (16). Of note, emm74 had not been identified in the region before and was associated with outbreaks in an under-housed population in Southern Ontario (17), thus raising the possibility that no protective immunity existed in the population. Unfortunately, we were unable to obtain emm-typing to determine whether the outbreak was triggered by a new, nephritogenic strain of GAS. Furthermore, regional hospitals and clinics noted an increase in the number of patients presenting with skin and soft-tissue infections during that period (16).

The interconnectedness between GAS-related disease presentations remains poorly understood in this population. While the rarity of PSGN in high-income settings in Ontario may not warrant active surveillance, we argue that adding PSGN to the reportable disease list would enhance knowledge and awareness surrounding transmission dynamics of GAS, which in turn could inform intervention.

Unlike acute rheumatic fever, treatment of initial GAS infection does not prevent PSGN, so public health efforts to address PSGN need to focus on primary prevention. Indigenous communities in Australia have high rates of GAS infections that are associated with inadequate water and housing capacity; improved housing decreased skin infections and positively impacted child health $(18,19)$. The First Nations community described in this report, like 60 other First Nations communities in Canada, was under a boil-water advisory at the time of the outbreak (20). Overcrowding in housing is well recognized in many First Nations communities and is the subject of the newly developed Nishnawbe Aski Nation Housing Strategy (21). Improving housing and other environmental determinants of health is grounded in human rights, and ongoing inequities trace back to the effects of colonization and poverty.

Preventing infectious diseases and their sequelae requires a broad, multifaceted approach. A recent Canadian Medical Association Journal editorial identified a two-fold greater likelihood of dying from a preventable cause in Canada's poorer communities, including First Nations, than in the most affluent neighbourhoods (22). The authors referenced New Zealand's "well-being budget," which includes social determinants of health in the healthcare equation with substantial investment in Indigenous peoples, mental healthcare and poverty reduction (23). There is much Canada can learn from this approach. PSGN is a prime example of a syndemic disease, where particular environmental, economic, social, legal, colonial and political contexts mutually potentiate each other with harmful consequences (24).

Public health response to cases and outbreaks of reportable communicable diseases in remote northern First Nations communities in Ontario is typically led by ISC and implemented at the front line by federal community health nurses. Outbreak management involved collaboration with the local Indigenous health services organization, SLFNHA, and an infectious disease specialist and family physicians from Sioux Lookout, who are funded by the province. A pre-existing working relationship between all partner organizations and individual members, as well as knowledge of the realities of healthcare delivery in a remote and isolated setting, facilitated the rapid formation of an outbreak management team. The team brought together expertise and experience at all levels and enabled rigorous protocol development that "fit" the setting, and the development of appropriate educational material. Strong community support, by community leadership in particular, ensured community engagement and the successful screening of the paediatric population (95\%) and contact tracing.

\section{Strengths and limitations}

Geography presents challenges for medical care in remote communities; access to paediatricians and nephrologists requires emergency medical evacuation for seriously ill patients or elective travel to Sioux Lookout and subsequent specialty referral to either Thunder Bay, Ontario, or Winnipeg, Manitoba. The absence of an existing protocol slowed the implementation of screening, which occurred eight weeks after the initial case presentation, and recovered or subclinical cases may have been missed. The absence of accurate prospective surveillance impedes early identification of outbreaks and underestimates the true burden of PSGN particularly in low-resource settings in Canada. Furthermore, limited capacity at the regional laboratory to store and process the potential number of swabs collected during screening prevented microbiologic confirmation of GAS-related skin sores among children and adults, as well as emm-typing of GAS strains. 
Although no additional cases of PSGN were identified in the weeks following the intervention, the length of time between the declaration of the outbreak and the response, as well as the lack of accurate pre and post-outbreak surveillance data precludes any conclusions on the effectiveness of the intervention in curbing the outbreak. The strength of the initiative was the degree of community involvement and mobilization, engendering disease awareness and acknowledging the concerted interagency efforts to improve community health.

\section{Conclusion}

This first reported outbreak of PSGN in Canada occurred in a remote First Nations community in Ontario. We developed a community-based response protocol where collaboration between all partners was critical; this can serve as a model for the management of future PSGN outbreaks.

In the absence of mandatory reporting, the burden of PSGN remains underappreciated and could undermine upstream and downstream public health interventions. The public health management of PSGN requires the decolonization of legal, political, social and economic structures to allow rapid identification and management of outbreaks and primary prevention.

\section{Authors' statement}

\section{JJ — Project administration, resources}

NB - Conceptualization, data curation, investigation, project administration, writing-review \& editing

$\mathrm{RH}$ - Conceptualization, data curation, investigation, project administration, writing-review \& editing

JP — Data curation

LK - Writing-original draft, writing-review \& editing

SM - Writing-original draft, writing-review \& editing YS - Conceptualization, data curation, investigation, project administration, writing-review \& editing, validation, formal analysis

The content and view expressed in this article are those of the authors and do not necessarily reflect those of the Government of Canada.

\section{Competing interests}

None.

\section{References}

1. Nissenson AR, Baraff LJ, Fine RN, Knutson DW. Poststreptococcal acute glomerulonephritis: fact and controversy. Ann Intern Med 1979;91(1):76-86. DOI PubMed
2 Walker MJ, Barnett TC, McArthur JD, Cole JN, Gillen CM, Henningham A, Sriprakash KS, Sanderson-Smith ML, Nizet V. Disease manifestations and pathogenic mechanisms of Group A Streptococcus. Clin Microbiol Rev 2014;27(2):264-301. DOI PubMed

3. VanDeVoorde RG 3rd. Acute poststreptococcal glomerulonephritis: the most common acute glomerulonephritis. Pediatr Rev 2015;36(1):3-12. DOI PubMed

4. Carapetis JR, Steer AC, Mulholland EK, Weber M. The global burden of group A streptococcal diseases. Lancet Infect Dis 2005;5(11):685-94. DOI PubMed

5. Health Protection and Promotion Act, R.S.O. 1990, c. H.7. Toronto (ON): Government of Ontario; 2020 (accessed 2020-09-28). https://www.ontario.ca/laws/ statute/90h07

6. Loewen K, Kelly L, Olivier C, Tobe S, Kirlew M, Saginur R, Schreiber Y. Acute post-streptococcal glomerulonephritis in northwestern Ontario: a six-year retrospective study. JAMMI 2016;1(3):17-24. DOI

7. Ontario Agency for Health Protection and Promotion (Public Health Ontario), Provincial Infectious Diseases Advisory Committee. Recommendations on public health management of invasive group a streptococcal (iGAS) Disease in Ontario. Toronto (ON): Government of Ontario; 2014 (accessed 2020-09-28). https://www. publichealthontario.ca/-/media/documents/I/2014/igasmanagement-recommendations.pdf?la=en

8. Northern Territory Government, Department of Health and Family. Northern Territory guidelines for acute post-streptococcal glomerulonephritis 2010. Casuarina (NT): Department of Health and Families; (updated 2010-06; accessed 2020-08-08). https://digitallibrary.health.nt.gov. au/prodjspui/bitstream/10137/444/1/NT\%20guidelines $\% 20$ for\%20control\%20of\%20APSGN.pdf

9. APSGN Task Force Disease Control Team 91941647. Acute post-streptococcal glomerulonephritis. Kimberley control measures 2014. Government of Western Australia, WA Country Health Service Kimberley Population Health Unit; 2014 (accessed 2020-02-09). http://kams.org.au/ wp-content/uploads/2016/11/Acute-Post-StreptococcalGlomerulonephritis-APSGN.pdf

10. Marshall CS, Cheng AC, Markey PG, Towers RJ, Richardson LJ, Fagan PK, Scott L, Krause VL, Currie BJ. Acute post-streptococcal glomerulonephritis in the Northern Territory of Australia: a review of 16 years data and comparison with the literature. Am J Trop Med Hyg 2011;85(4):703-10. DOI PubMed

11. Speers DJ, Levy A, Gichamo A, Eastwood A, Leung MJ. M protein gene (emm type) analysis of group A Streptococcus isolates recovered during an acute glomerulonephritis outbreak in northern Western Australia. Pathology 2017;49(7):765-9. DOl PubMed 
12. Norton R, Smith HV, Wood N, Siegbrecht E, Ross A, Ketheesan N. Invasive group A streptococcal disease in North Queensland (1996 - 2001). Indian J Med Res 2004;119 Suppl:148-51. PubMed13. Gordon J, Kirlew M, Schreiber Y, Saginur R, Bocking N, Blakelock B, Haavaldsrud M, Kennedy C, Farrell T, Douglas L, Kelly L. Acute rheumatic fever in First Nations communities in northwestern Ontario: social determinants of health "bite the heart". Can Fam Physician 2015;61(10):881-6. PubMed

14. Madden S, Kelly L. Update on acute rheumatic fever: it still exists in remote communities. Can Fam Physician 2009;55(5):475-8. PubMed

15. Loewen K, Bocking N, Matsumoto CL, Kirlew M, Kelly L. Epidemiologic features of invasive group A Streptococcus infection in a rural hospital: 6-year retrospective report and literature review. Can J Rural Med 2017;22(4):131-8. PubMed

16. Ontario Agency for Health Protection and Promotion. Invasive group A streptococcal disease in Ontario: 2016-17 seasonal summary. Toronto (ON): Public Health Ontario; 2018. https://www.publichealthontario.ca/-/media/ documents/S/2018/seasonal-summary-igas-2016-17 pdf?la=en

17. Athey TB, Teatero S, Sieswerda LE, Gubbay JB, Marchand-Austin A, Li A, Wasserscheid J, Dewar K, McGeer A, Williams D, Fittipaldi N. High Incidence of invasive group A Streptococcus disease caused by strains of uncommon emm types in Thunder Bay, Ontario, Canada. J Clin Microbiol 2016;54(1):83-92. DOI PubMed
18. Bailie RS, Stevens MR, McDonald E, Halpin S, Brewster D, Robinson G, Guthridge S. Skin infection, housing and social circumstances in children living in remote Indigenous communities: testing conceptual and methodological approaches. BMC Public Health 2005;5:128-39. DOl PubMed

19. Currie BJ, Carapetis JR. Skin infections and infestations in Aboriginal communities in northern Australia. Australas J Dermatol 2000;41(3):139-43. DOI PubMed

20. Indigenous Services Canada. Water in First Nations communities. Ottawa (ON): Government of Canada; (updated 2020-12-02; accessed 2020-04-03). https://www. sac-isc.gc.ca/eng/1506514143353/1533317130660

21. Nishnawbe Aski Nation. NAN Housing Strategy. Thunder Bay (ON): Nishnawbe Aski Nation; 2018 (accessed 2020-04-03). http://www.nan.on.ca/upload/ documents/nan-housing_position_paper-final.pdf

22. Boozary A, Laupacis A. The mirage of universality: Canada's failure to act on social policy and health care. CMAJ 2020;192(5):E105-6. DOI PubMed

23. Anderson M, Mossialos E. Beyond gross domestic product for New Zealand's wellbeing budget. Lancet Public Health 2019;4(7):e320-1. DOI PubMed

24. The Lancet. Syndemics: health in context. Lancet 2017;389(10072):881. DOI PubMed

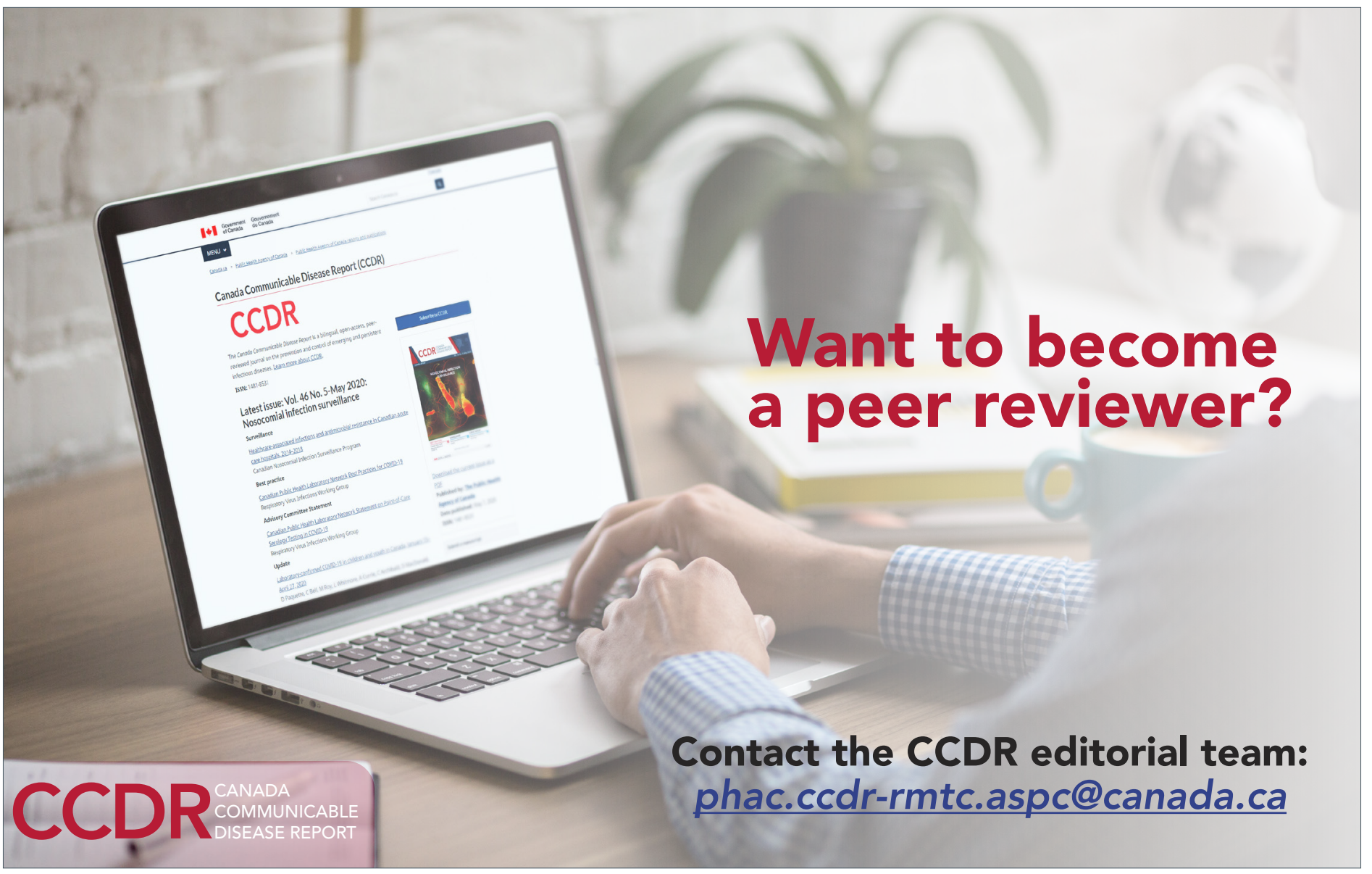

